\title{
Hydrocarbon productivities in different Botryococcus strains: comparative methods in product quantification
}

\author{
Ela Eroglu • Shigeru Okada • Anastasios Melis
}

Received: 23 May 2010 /Revised and accepted: 13 August 2010/Published online: 2 September 2010

(C) The Author(s) 2010. This article is published with open access at Springerlink.com

\begin{abstract}
Six different strains of the green microalgae Botryococcus belonging to the A-race or B-race, accumulating alkadiene or botryococcene hydrocarbons, respectively, were compared for biomass and hydrocarbon productivities. Biomass productivity was assessed gravimetrically upon strain growth in the laboratory under defined conditions. Hydrocarbon productivities were measured by three different and independent experimental approaches, including density equilibrium of the intact cells and micro-colonies, spectrophotometric analysis of hydrocarbon extracts, and gravimetric quantitation of eluted hydrocarbons. All three hydrocarbon-quantitation methods yielded similar results for each of the strains examined. The B-race microalgae Botryococcus braunii var. Showa and Kawaguchi-1 constitutively accumulated botryococcene hydrocarbons equivalent to $30 \%$ and $20 \%$, respectively, of their overall biomass. The A-race microalgae Botryococcus braunii, varieties Yamanaka, UTEX 2441 and UTEX LB572 constitutively accumulated alkadiene hydrocarbons ranging from $14 \%$ to $13 \%$ and $10 \%$ of their overall biomass, respectively. Botryococcus sudeticus (UTEX 2629), a morphologically different green microalga, had the lowest hydrocarbon accumulation, equal to about $3 \%$ of its overall biomass. Results validate the density equilibrium and spectrophotometric analysis methods in the quantitation
\end{abstract}

\footnotetext{
E. Eroglu $\cdot$ A. Melis $(\bowtie)$

Department of Plant and Microbial Biology,

University of California,

Berkeley, CA 94720-3102, USA

e-mail: melis@berkeley.edu

S. Okada

Laboratory of Aquatic Natural Products Chemistry,

Graduate School of Agricultural and Life Sciences,

The University of Tokyo,

Tokyo $113-8657$, Japan
}

of botryococcene-type hydrocarbons. These analytical advances will serve in the screening and selection of $B$. braunii and of other microalgae in efforts to identify those having a high hydrocarbon content for use in commercial applications.

Keywords Botryococcus · Alkadiene · Botryococcene · Hydrocarbons · Carotenoid · Chlorophyll

\section{Introduction}

Green microalgae of the genus Botryococcus are noted in the literature because of their hydrocarbon-accumulating property. On the basis of their characteristics, thirteen different species of Botryococcus have been identified, having slightly different morphological, physiological and biochemical properties (Wolf and Cox 1981; Komárek and Marvan 1992; Okada et al. 1995; Metzger and Largeau 2005). Strains of B. braunii have been studied extensively as they grow photo-autotrophically (Beakes and Cleary 1999) and accumulate unusually high amounts of hydrocarbon molecules (Metzger et al. 1988; Lupi et al. 1994). They can be cultured either in liquid cultures (Lupi et al. 1994) or on immobilized matrices (Bailliez et al. 1988; deBashan and Bashan 2010). These features make Botryococcus an interesting candidate for the photosynthetic production of hydrocarbons (Wake and Hillen 1980), thus providing a potential source of renewable and sustainable biofuels (Sawayama et al. 1995; Kita et al. 2010).

Chemical analyses of wild type samples and laboratory grown strains have led to recognition of three different Botryococcus races, classified according to the type of hydrocarbons produced: Race A produces $\mathrm{C} 25$ to C31, oddnumbered n-alkadienes and alkatrienes (Banerjee et al. 
2002; Grice et al. 1998). Hydrocarbon products of the B-race include different methylated triterpenes, known as "botryococcenes", with the chemical formula $\mathrm{C}_{\mathrm{n}} \mathrm{H}_{2 \mathrm{n}-10}$, where $\mathrm{n}=30-37$ (Rao et al. 2007; Raja et al. 2008). Botryococcenes can exist as isomers with the same number of carbons but with different structures. In natural populations of B. braunii, hydrocarbon content has been reported to range widely, from nearly zero up to $86 \%$ of dry cell weight (Wolf and Cox 1981; Brown et al. 1969). However, Metzger and Largeau (2005) reported that very high proportions of hydrocarbon content (e.g. 86\%) may be observed during the very late stationary phase and may be the result of cell lysis and loss of biomass. The $L$ race yields a single $\mathrm{C}_{40}$ isoprenoid hydrocarbon derivative of lycopadiene (Metzger and Casadevall 1987).

While Botryococcus races A and B are widely distributed in brackish and freshwater such as alpine, temperate and tropical lakes, those of race $\mathrm{L}$ are only observed in water samples collected in the tropics. Algae of race A exhibit the most variable hydrocarbon content, ranging from $0.4 \%$ to $60 \%$ of their dry cell weight (Metzger and Largeau 2005). By comparison, hydrocarbon content in race B generally varies between $10-40 \%$ of the dry cell weight (Metzger and Largeau 2005; Okada et al. 1995). Algae of race L show a hydrocarbon content ranging from $0.1 \%$ to $8.0 \%$ (Metzger and Largeau 2005).

The aforementioned studies suggested great variability in hydrocarbon yields among different species and strains of Botryococcus (Metzger and Largeau 2005; Banerjee et al. 2002; Raja et al. 2008; Lee et al. 2010; Samori et al. 2010). Some of these could probably be attributed to growth conditions, photo-bioreactor design and nutrients employed. Thus, direct comparisons on productivity among different strains may not be valid. However, there is a need to directly compare yields and productivity of different Botryococcus strains so as to properly assess their potential for commercial exploitation.

In the present work, six different Botryococcus strains (two B-Race, and four A-Race) were compared by morphology, productivity and hydrocarbon accumulation. A variety of methods were employed, including density equilibrium, spectrophotometry and gravimetric approaches for multiple independent quantifications of $B$. braunii biomass and yield of hydrocarbon accumulation. The results showed yields of hydrocarbon accumulation by B-race strains of $B$. braunii substantially greater than those of A-race. Moreover, botryococcene hydrocarbons of the B-race could be readily and quantitatively separated from the biomass, unlike hydrocarbons of the A-race, where cell rupture was observed to occur, causing pigment extraction and co-isolation along with the A-race hydrocarbons. Further, results from the comparative analyses in this work showed that botryococcene triterpenoid hydrocarbon accumulation by B-race microalgae is superior to that of diene and triene accumulation by A-race microalgae, both in terms of yield and specificity of hydrocarbon separation from the biomass.

\section{Materials and methods}

Organisms, growth conditions, and biomass quantitation

Cells of six different Botryococcus species and Chlamydomonas reinhardtii were grown in $500 \mathrm{~mL}$ of modified Chu13 medium (Largeau et al. 1980) in 2 L conical Fernbach flasks. Botryococcus braunii var. Showa was obtained from the University of California (UC Berkeley Herbarium Accession No UC147504) (Nonomura 1988). Botryococcus braunii strains Kawaguchi-1 and Yamanaka were obtained from the University of Tokyo (Okada et al. 1995). Botryococcus braunii UTEX 2441, UTEX LB572 and B. sudeticus (UTEX 2629) were obtained from the culture collection of the University of Texas.

Cells were grown at $25^{\circ} \mathrm{C}$ under continuous cool-white fluorescent illumination at an incident intensity of $50 \mu \mathrm{mol}$ photons $\mathrm{m}^{-2} \mathrm{~s}^{-1}$ (PAR) upon orbital shaking of the Fernbach flasks at $60 \mathrm{rpm}$ (Lab-line Orbit Shaker No.3590). Flasks were capped with Styrofoam stoppers, allowing for sufficient aeration, i.e., gas exchange between the culture and the outside space. Two-week old cultures were used to inoculate new cultures, such that the starting cell concentration of the newly inoculated culture was at about $0.1 \mathrm{~g}$ dry weight (dw) per liter. To measure the rate of growth under continuous-fed growth conditions, a fixed fraction of the culture ( $40 \%$ of the total volume) was periodically removed from the Fernbach flasks and replaced by an equal volume of fresh growth medium. Dry cell weight and hydrocarbon content of the harvested biomass, measured in $\mathrm{g} \mathrm{L}^{-1}$ of harvested volume, was plotted as a function of time. The frequency of culture harvesting and medium replacement was $24 \mathrm{~h}$ for B. sudeticus (UTEX 2629), $48 \mathrm{~h}$ for B. braunii var. Showa, B. braunii Yamanaka, B. braunii UTEX LB572, and $72 \mathrm{~h}$ for $B$. braunii Kawaguchi-1 and B. braunii UTEX 2441.

Algal growth and biomass accumulation was measured gravimetrically and expressed in terms of dry weight (dw) per volume of culture $\left(\mathrm{g} \mathrm{L}^{-1}\right)$. Dry cell weight analysis was carried out upon filtering the samples through Millipore Filter $(8 \mu \mathrm{m}$ pore size for Botryococcus; $0.22 \mu \mathrm{m}$ for Chlamydomonas). The cell weight was measured as recently described (Eroglu and Melis 2010), after drying the filters at $80^{\circ} \mathrm{C}$ for $24 \mathrm{~h}$ in a lab oven, and measurement of the dry cell matter (dw). When applied, dispersion of the microcolonies was achieved by sonication of the samples for 4 min with a Branson sonifier, operated at a power output of 7 and 50\% duty cycle (Eroglu and Melis 2009). Sonication processes were carried out at $4^{\circ} \mathrm{C}$. 
Density equilibrium measurements

Sucrose density gradient centrifugation of culture aliquots, spanning a sucrose concentration range from $10-80 \%(\mathrm{w} / \mathrm{v})$, and having a concentration increment step of $10 \%$, were prepared. Sucrose was dissolved in a solution containing $10 \mathrm{mM}$ EDTA and $5 \mathrm{mM}$ HEPES KOH (pH 7.5). Sucrose solutions were set in the gradient, as recently described in work from this lab on the application of the density equilibrium concept for hydrocarbon quantifications (Eroglu and Melis 2009). Samples containing microcolonies, single cells, or subcellular particles of interest, were carefully layered on top of the preformed gradient, followed by centrifugation of the polyallomer tubes in a JS-13.1 swing bucket Beckman rotor, at an acceleration of $20,000 \mathrm{~g}$ for $30 \mathrm{~min}$ at $4^{\circ} \mathrm{C}$. The density equilibrium position of the samples was noted at the end of this centrifugation. Sonication of samples, when appropriate, was applied for $4 \mathrm{~min}$ with a Branson sonifier, operated at a power output of 7 and $50 \%$ duty cycle.

Spectrophotometric quantification of hydrocarbons

Botryococcus cells were harvested from the liquid media by filtration. Approximately $1 \mathrm{~g}$ cake of Botryococcus wet weight (ww) was incubated at $100^{\circ} \mathrm{C}$ for $10 \mathrm{~min}$. Following the heat treatment, the cell cake was mixed with $1 \mathrm{~g}$ of glass beads $(0.5 \mathrm{~mm}$ diameter), and resuspended in $10 \mathrm{~mL}$ of heptane (HPLC Grade - Fischer Scientific). The cells-inheptane suspension was vortexed for $15 \mathrm{~min}$ at maximum speed (Fisher Vortex Genie-2). Vortexing of Botryococcus biomass with glass beads in the presence of heptane resulted in a release of extracellular hydrocarbons from the micro-colony and their subsequent solubilization in the heptane phase. Following aqueous/organic two-phase partition (Eroglu and Melis 2010), the upper heptane phase was collected for measurement of the absorbance spectra in a UV/Visible spectrophotometer. Extractable triterpenoid (botryococcene) hydrocarbons were determined from the absorbance in the UV-C region $\left(\lambda_{\max }=\sim 190 \mathrm{~nm}\right)$, whereas associated carotenoids were determined from the absorbance of the heptane solution in the blue region of the spectrum $\left(\lambda_{\max }=\sim 450 \mathrm{~nm}\right)$. Total amounts of botryococcene (Btc) and carotenoid (Car), extracted from the various Botryococcus cultures were calculated on the basis of molar extinction coefficients $\varepsilon$ for botryococcene $\left(\varepsilon_{190} \mathrm{~nm}=90 \pm 5 \mathrm{mM}^{-1} \mathrm{~cm}^{-1}\right)$ and carotenoids $\left(\varepsilon_{450} \mathrm{~nm}=\right.$ $165 \pm 5 \mathrm{mM}^{-1} \mathrm{~cm}^{-1}$ ) (Eroglu and Melis 2010).

Spectrophotometric quantitation of chlorophyll (Chl) and carotenoid (Car) content

A known amount of culture pellet was mixed with a known volume of methanol. The methanol-biomass mixture was vortexed at high speed until the color of the biomass became white, indicating full extraction of intracellular pigments. The crude extract was filtered and the absorbance of the green methanolic phase was measured at 470, 652.4 and $665.2 \mathrm{~nm}$. Total carotenoid, chlorophyll $(a+b)$ content, $\mathrm{Chl} a / \mathrm{Chl} b$ and the $\mathrm{Car} / \mathrm{Chl}$ ratios were determined according to Lichtenthaler and Buschmann (2001).

Gravimetric quantitation of lipophilic extracts

The total methanol extract of cells was carefully collected and evaporated to dryness under a stream of air for gravimetric quantitation. Such extract contains all lipophilic cellular compounds, including diglycerides (DG), Chl, Car, and potentially accumulating hydrocarbons. The amount of accumulating hydrocarbons was estimated upon subtracting the diglycerides (DG), Chl, and Car content from the overall lipophilic cell extracts. This was accomplished upon consideration of a known (and constant among microalgae) DG/Chl ratio, derived for the model microalga Chlamydomonas reinhardtii. The latter does not accumulate terpenoid or alkadiene hydrocarbons. Hence, the vast majority of acyl-glycerols in C. reinhardtii are DGs.

\section{Statistical analyses}

Statistical analysis of the results is based on three independent measurements. Results are expressed as a mean \pm standard deviation of 3 independent measurements.

\section{Results}

\section{Cell growth}

Orbital shaking of Botryococcus cultures in conical Fernbach flasks causes hydrocarbon-laden microcolonies to "centrifuge" to the center of the flask, leaving a clear growth medium in its surroundings. Figure 1 shows a photograph of a group of Fernbach flasks, taken while on an orbital shaker with various Botryococcus cultures. It is seen that cultures of B. braunii var. Showa (Fig. 1a), Kawaguchi-1 (Fig. 1b), Yamanaka (Fig. 1c), UTEX 2441 (Fig. 1d), and UTEX LB572 (Fig. 1e) all "centrifuge" to the center of the $500 \mathrm{~mL}$ growth medium. Conversely, Fig. If shows a culture of $B$. sudeticus (UTEX 2629), in which the cell suspension is uniform throughout the liquid medium during orbital shaking.

The tendency of the micro-colonies to segregate toward the center of the growth medium upon orbital shaking (Fig. 1) is apparently a result of the centrifugal forces 
Fig. 1 Botryococcus cells, grown in $500 \mathrm{~mL}$ of modified Chu-13 medium in conical Fernbach flasks upon orbital shaking. Note that (a) Botryococcus braunii var. Showa, (b) Botryococcus braunii

Kawaguchi-1, (c) Botryococcus braunii Yamanaka, (d) Botryococcus braunii UTEX 2441, (e) Botryococcus braunii UTEX LB572 micro-colonies centrifuging to the center of the $\mathrm{H}_{2} \mathrm{O}$ based growth medium, whereas (f) Botryococcus sudeticus (UTEX 2629) cultures made uniform suspension a

Botryococcus braunii (Showa)

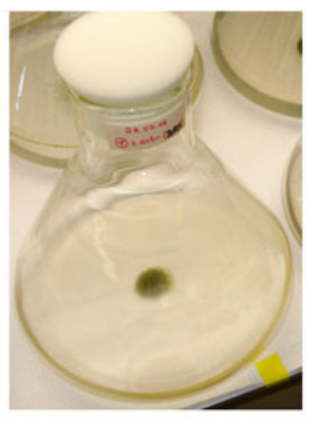

d

\section{Botryococcus braunii} (UTEX-2441)

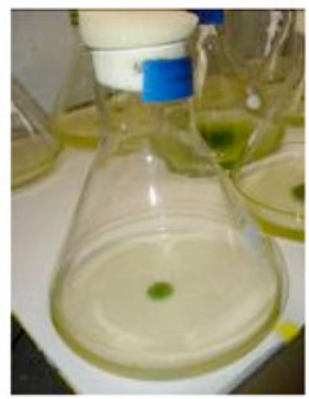

b

Botryococcus braunii (Kawaguchi-1)

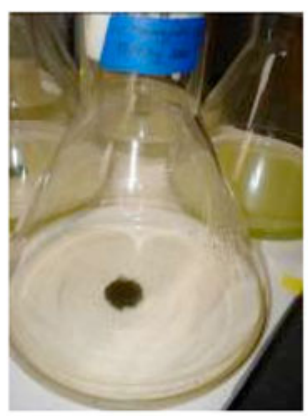

\section{e}

\section{Botryococcus braunii} (UTEX-LB572)

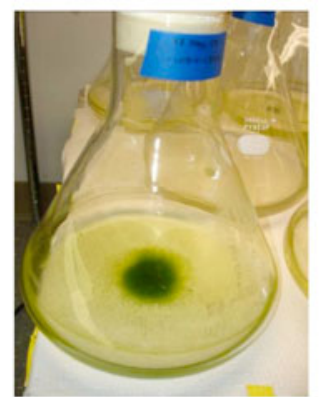

C

Botryococcus braunii (Yamanaka)

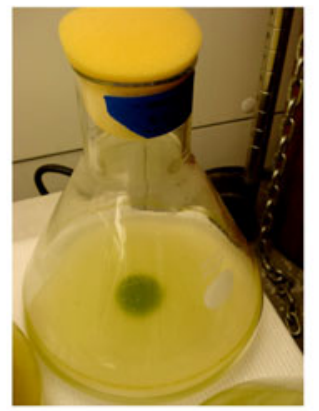

f

Botryococcus sudeticus (UTEX-2629)

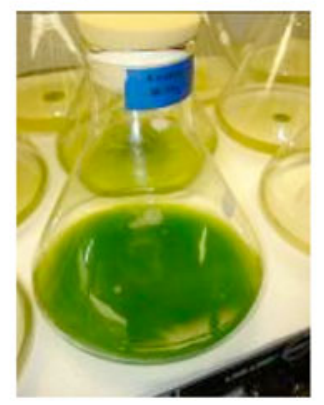

applied to the culture and a consequence of the hydrocarbon content of the micro-colonies. This contention is supported by observations of other microalgae that do not accumulate hydrocarbons. For example, unicellular Chlamydomonas reinhardtii with a thick cell wall, and Dunaliella salina with no cell wall, have substantially different "Density Equilibrium" properties (Eroglu and Melis 2009). When cultivated under similar orbital conditions, both showed a cell suspension uniformly dispersed throughout the liquid medium (not shown). Further, mechanical dispersion of B. braunii var. Showa micro-colonies, either by sonication or glass bead vortexing of the cultures in growth media, resulted in extensive loosening-up of the normally tightly packed cells in the three-dimensional micro-colonies and a substantial release of the botryococcene hydrocarbons from the micro-colony structure. A sucrose gradient centrifugation, conducted with such mechanically dispersed micro-colonies, efficiently separated the botryococcene hydrocarbons from the microalgal cells (Fig. 5 in Eroglu and Melis 2010). Botryococcene-less cells, when re-suspended in growth media, became uniformly dispersed upon orbital shaking of the culture (not shown). It may be inferred that a micro-colony structure, laden with low-density hydrocarbons, is essential for the tendency of the micro-colonies to segregate toward the center of the growth medium upon orbital shaking (Fig. 1 a-e).
Conversely, it may also be inferred that B. sudeticus, with cells uniformly dispersed in the growth medium (Fig. 1f) does not accumulate hydrocarbons to the same extend as the case is with the $B$. braunii strains.

Growth rates of the different Botryococcus strains were obtained upon cultivation under identical conditions (see Fig. 1) in continuous fed cultures. Biomass accumulation was measured upon periodic removal of a fixed fraction of the culture ( $40 \%$ of the culture volume) and replacement by an equal volume of fresh growth medium. Under these conditions, cultures remained in an active growth phase. Productivity estimates were based on the volume of growth medium that was used-and-replaced in this continuous-fed process, rather than on the steady-state total volume of the culture. The rationale for choosing this basis for the productivity of the culture is that, in a commercial hydrocarbons-production continuous-fed process, costs associated with the replacement volume would figure prominently, not so much those of the steady-state volume of the culture. The cumulative dry cell weight of the biomass from each Botryococcus strain is shown in Fig. 2. Rates of biomass accumulation, obtained from the slopes of the straight lines, revealed that B. sudeticus (UTEX 2629)

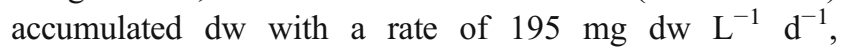
Fig. 2f), B. braunii Yamanaka accumulated $d w$ with a rate of $135 \mathrm{mg} \mathrm{dw} \mathrm{L}^{-1} \mathrm{~d}^{-1}$, Fig. 2c), followed by Showa 


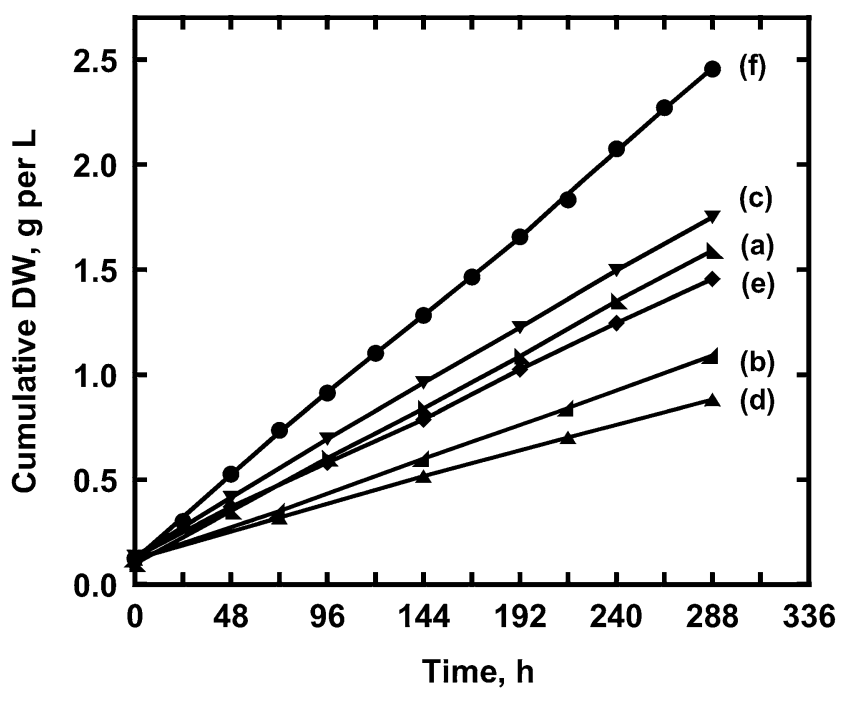

Fig. 2 Cumulative biomass productivities of Botryococcus strains in continuous fed cultures. Data points indicate the time when a fixed fraction of the culture ( $40 \%$ of the culture volume) was harvested and replaced by an equal volume of fresh growth medium. Cells were grown in $500 \mathrm{~mL}$ of modified Chu-13 medium in conical Fernbach flasks upon orbital shaking. The slopes of the straight lines defined the corresponding rates of biomass accumulation, equal to (a) $125 \mathrm{mg} \mathrm{dw}$

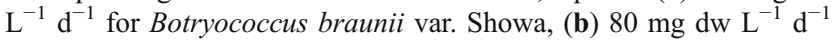
for Kawaguchi-1, (c) $135 \mathrm{mg} \mathrm{dw} \mathrm{L}{ }^{-1} \mathrm{~d}^{-1}$ for Yamanaka, (d) $60 \mathrm{mg} \mathrm{dw}$ $\mathrm{L}^{-1} \mathrm{~d}^{-1}$ for UTEX 2441, (e) $110 \mathrm{mg} \mathrm{dw} \mathrm{L}^{-1} \mathrm{~d}^{-1}$ for UTEX LB572, and (f) $195 \mathrm{mg} \mathrm{dw} \mathrm{L}^{-1} \mathrm{~d}^{-1}$ for Botryococcus sudeticus (UTEX 2629)

(125 mg dw L ${ }^{-1} \mathrm{~d}^{-1}$, Fig. 2a), UTEX LB572 (110 mg dw $\mathrm{L}^{-1} \mathrm{~d}^{-1}$, Fig. 2e), Kawaguchi-1 (80 mg dw L $\mathrm{L}^{-1} \mathrm{~d}^{-1}$, Fig. 2b) and UTEX 2441 (60 $\mathrm{mg} \mathrm{dw} \mathrm{L}^{-1} \mathrm{~d}^{-1}$, Fig. 2d).

\section{Micro-structural organization of Botryococcus strains}

Botryococcus braunii B-race typically have amorphous three-dimensional micro-colony structures, characterized by a botryoid appearance of the micro-colony, where individual grape seed-like, or pyriform-shaped cells are held together by a surrounding hydrocarbon matrix (Metzger and Largeau 2005; Eroglu and Melis 2010). These micro-colonies can grow in size to reach up to $1 \mathrm{~mm}$ in diameter (Bachofen 1982). The bulk of the B. braunii hydrocarbons are stored within the outer cell walls and in the extracellular spaces of the micro-colony structure (Largeau et al. 1980). Wolf and co-workers (Wolf et al. 1985) calculated that only approximately $7 \%$ of the botryococcenes are intracellular with the majority of the microcolony hydrocarbons forming an extracellular matrix. Likewise, Largeau et al. (1980) reported that 95\% of the botryococcenes are located in the extracellular pool of hydrocarbons.

However, there is morphological heterogeneity between the different strains of Botryococcus-type microalgae. Microscopic examination of the strains discussed in this work (Fig. 3a-f) showed variations both in the size and shape of the cells, which can be more or less embedded in the matrix, and by the presence or absence of refracting threads, forming pili-like structures and clearly linking clusters of cells, thus leading to the formation of large colonies. These characteristics are clearly seen in the B-race of B. braunii, e.g. Showa (Fig. 3a), and Kawaguchi-1 (Fig. 3b), they are also discernible in the Arace of $B$. braunii, e.g. Yamanaka (Fig. 3c), but are less well developed in UTEX 2441 (Fig. 3d), and LB572 (Fig. 3e). Botryococcus sudeticus (UTEX 2629) has a distinctly different cell shape from all of the preceding strains, consisting of perfectly spherical single cells without any apparent connectivity among them (Fig. 3f). It must be noted that on the basis of rRNA sequencing, Senousy et al. (2004) classified B. sudeticus in Chlorophyceae, suggesting that it belongs to a genus altogether different than Botryococcus. Microscopic visualization of strains in Fig. 3 will help the field in the proper identification of their Botryococcus samples, and will alleviate the often-erroneous treatment of invading green microalgae in scale-up cultures as part of the Botryococcus biomass.

\section{Density equilibrium properties of Botryococcus colonies}

Wet biomass cake (ww) and dry biomass weight (dw) analysis was carried out by filtering microalgal cultures through Millipore Filter ( $8 \mu \mathrm{m}$ pore size), followed by rinsing with distilled water and drying of the filters in a lab oven. This quantitative analysis provided a measure of the dw/ww ratios for each of the Botryococcus strains examined. Chlamydomonas reinhardtii (CC503) was employed in this experiment as a control. With the exception of Kawaguchi-1 and UTEX LB572, all other strains had dw/ww ratios of $0.24 \pm 0.06$ (w/w) (Table 1). These dw/ww ratios are greater from those measured with plant cells (Park and Kim 1993), reflecting the highdensity biomass and the lack of sizable water-filled vacuoles in microalgae. Table 1 also shows that UTEX LB572 appeared to have a rather low dw/ww ratio $0.08 \pm$ $0.02(\mathrm{w} / \mathrm{w})$, whereas Kawaguchi-1 appeared to have a much higher dw/ww ratio of $0.38 \pm 0.03(\mathrm{w} / \mathrm{w})$.

The average $\mathrm{dw} / \mathrm{ww}$ ratio of $0.24 \pm 0.06(\mathrm{w} / \mathrm{w})$ is at variance with some measurements in the literature. For example, the dry to wet weight ratio in $C$. reinhardtii and similar green microalgae was reported to be $0.1(\mathrm{w} / \mathrm{w})$ (Ward 1970). This difference is attributed to the different approaches employed in the wet weight determination of the cells. Filtration and the "wet cell cake" approach would tend to remove more water from the microalgae than centrifugation and wet pellet measurement. This is especially so for the oil containing microalgae, which are naturally difficult to precipitate in any type of centrifugation, resulting in a retention of significant amounts of water by the pellet. 
Fig. 3 Microscopic observations of a dispersed B. braunii var. Showa micro-colony, showing the grape-seed-like green cells for all $B$. braunii strains (a-e) and round green cells (f) Botryococcus sudeticus (UTEX 2629). Bars indicate $10 \mu \mathrm{m}$

\section{a} Botryococcus braunii
(Showa)

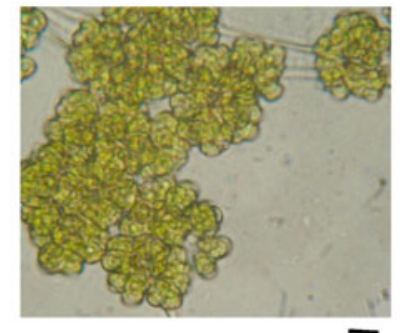

$10 \mu \mathrm{m}$

\section{d Botryococcus braunii} (UTEX-2441)

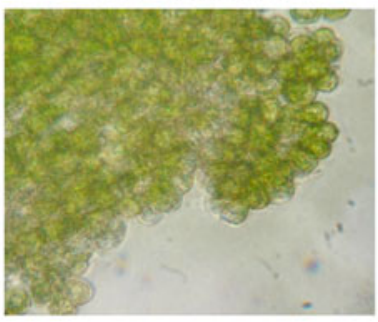

$10 \overline{\mu \mathrm{m}}$ b

Botryococcus braunii (Kawaguchi-1)

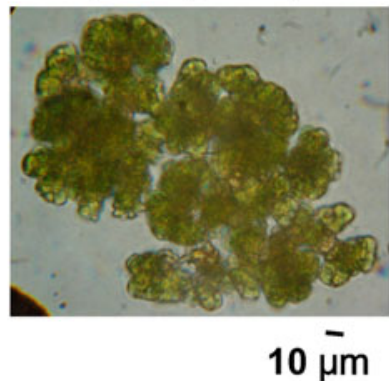

e Botryococcus braunii (LB-572)

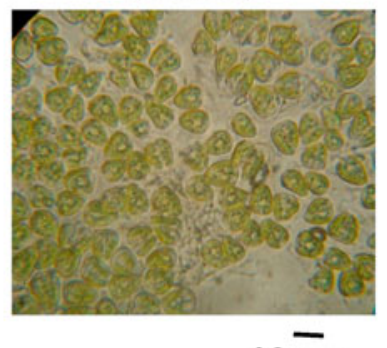

C Botryococcus braunii (Yamanaka)

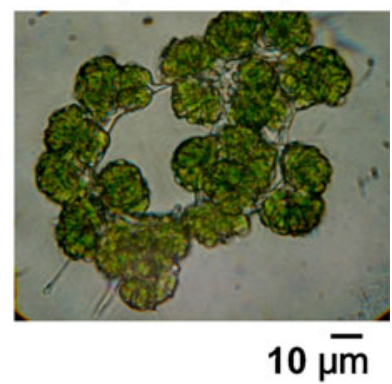

f Botryococcus sudeticus (UTEX-2629)

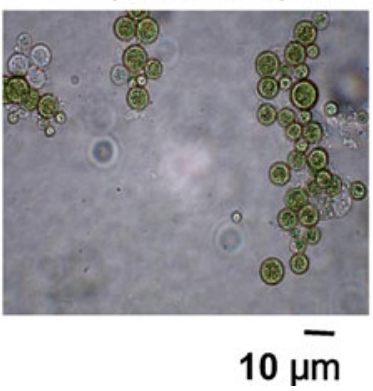

A direct density equilibrium measurement was recently reported, for the rapid in situ estimation of total lipid content in microalgae (Eroglu and Melis 2009). The method is based on the measurement of the density $(\rho)$ of live cells, or micro-colonies, from which the absolute lipid content of the cells can be calculated. This method was applied with each of the 6 Botryococcus strains examined in this work. Figure 4 shows the density equilibrium properties of the different strains following centrifugation in a $10-80 \%$ sucrose gradient. Two of the B-race strains (Showa and Kawaguchi-1) were the most buoyant among the Botryococcus strains examined. Showa micro-colonies floated on top of the $10 \%$ sucrose density, i.e. they displayed a density $\rho<1.039 \mathrm{~g} \mathrm{~mL}^{-1}$ (Fig. 4a). This is consistent with earlier measurements (Eroglu and Melis 2009), in which Showa micro-colony density was measured more precisely to be $\rho=1.031 \mathrm{~g} \mathrm{~mL}^{-1}$. Micro-colonies of
Kawaguchi-1 floated at about the $10 \%$ sucrose gradient step, i.e., they had an overall density $\rho=1.039 \mathrm{~g} \mathrm{~mL}^{-1}$ (Fig. 4b). Two different A-race strains (Yamanaka and UTEX 2441) displayed higher $\rho$ values, as their density equilibrium position in sucrose gradient was found to be in the top and bottom boundaries of the $30 \%$ sucrose step, respectively (Fig. 4c and Fig. 4d). The calculated absolute density for Yamanaka was approximately $\rho=1.10 \mathrm{~g} \mathrm{~mL}^{-1}$ (Fig. 4c) and for UTEX 2441 it was $\rho=1.14 \mathrm{~g} \mathrm{~mL}^{-1}$ (Fig. 4d). Similarly, strain LB572 (A-race) cells displayed a density equivalent to $\rho=1.23 \mathrm{~g} \mathrm{~mL}^{-1}$, as they equilibrated at about the $50 \%$ sucrose gradient step (Fig. 4e). On the other hand, Botryococcus sudeticus (UTEX 2629) proved to have the highest density of the samples examined, as it equilibrated at the $70-75 \%$ sucrose gradient step, corresponding to a $\rho=1.350-1.382 \mathrm{~g} \mathrm{~mL}^{-1}$ (Fig. 4f). The density equilibrium values measured for each of the six
Table 1 Dry weight (dw) to wet weight (ww) ratios and Density Equilibrium values for various Botryococcus species and Chlamydomonas reinhardtii (CC503). Density equilibrium values have been determined upon sucrose gradient centrifugation of live cultures

\begin{tabular}{lll}
\hline Strains & $\mathrm{dw} / \mathrm{ww}\left(\mathrm{g} \mathrm{g}^{-1}\right)$ & Density Equilibrium, $\rho_{\mathrm{S}}, \mathrm{g} \mathrm{mL}^{-1}$ \\
\hline B. braunii var. Showa & $0.18 \pm 0.04$ & 1.03 \\
B. braunii Kawaguchi-1 & $0.38 \pm 0.03$ & 1.08 \\
B. braunii Yamanaka & $0.20 \pm 0.02$ & 1.16 \\
B. braunii UTEX 2441 & $0.30 \pm 0.02$ & 1.20 \\
B. braunii UTEX LB572 & $0.08 \pm 0.02$ & 1.26 \\
B. sudeticus (UTEX 2629) & $0.22 \pm 0.03$ & 1.34 \\
C. reinhardtii (CC503) & $0.25 \pm 0.04$ & 1.35 \\
\hline
\end{tabular}




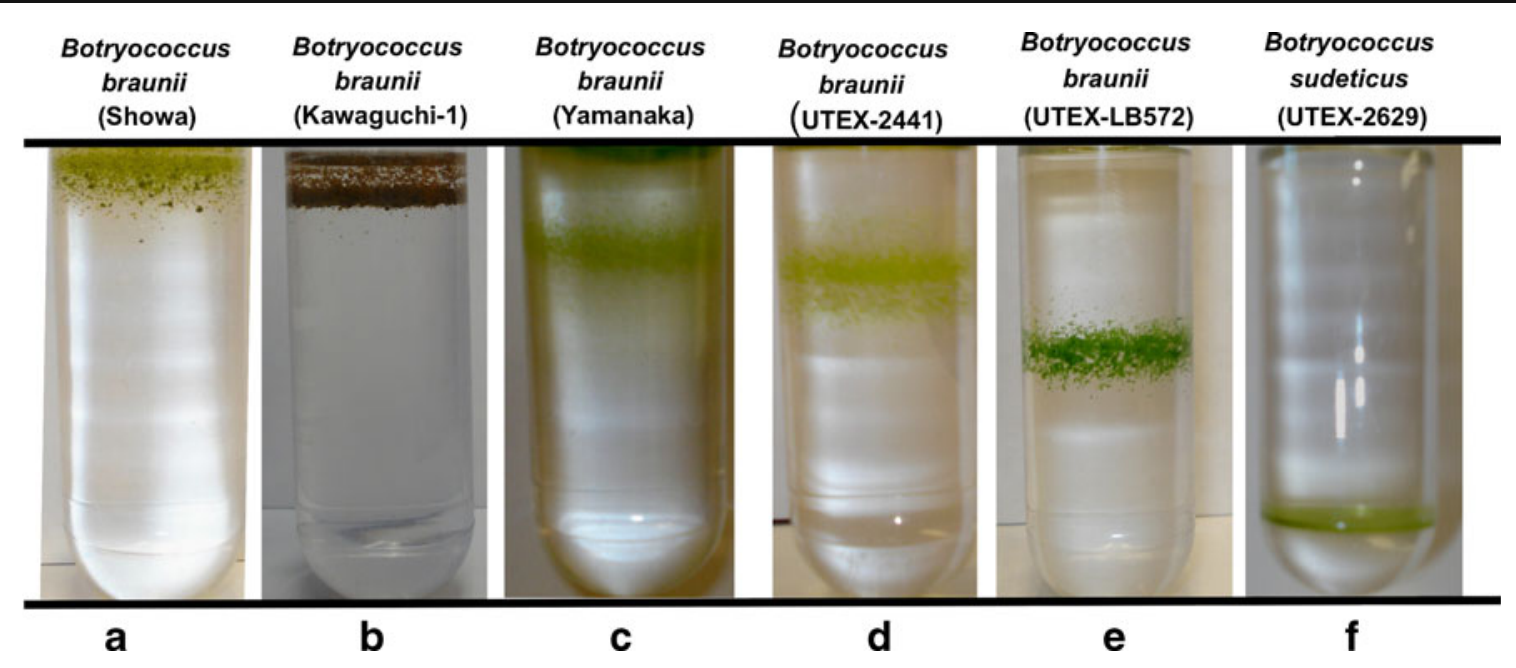

Fig. 4 In vivo buoyant densities of various live Botryococcus cells, sorted according to increasing buoyant density of the samples. (a) Botryococcus braunii var. Showa, (b) Kawaguchi-1, (c) Yamanaka, (d) UTEX 2441, (e) UTEX LB572, and (f) Botryococcus sudeticus (UTEX 2629). A 10-80\% (w/v) sucrose gradient was employed with a $10 \%$ increment among the gradient steps
Botryococcus strains are also summarized in Table 1. This analysis revealed that $B$. braunii var. Showa microcolonies have the lowest density equilibrium from the six strains examined.

In order to independently measure the contribution of hydrocarbons to the buoyant density of Showa and Kawaguchi-1 strains, the sonication and flotation method of Eroglu and Melis (2010) was employed. In this approach, micro-colonies are mechanically disrupted by sonication or vortexing with glass beads, followed by sucrose density gradient centrifugation. Mechanical dispersion of the microcolonies dislodges the hydrocarbons form the exterior of the cells, causing the former to float on top of the sucrose gradient (Eroglu and Melis 2010). Figure 5 shows the Density Equilibrium profile of sonicated Showa (Fig. 5a) and Kawaguchi-1 (Fig. 5b) micro-colonies. A yellowish-orange colored hydrocarbons fraction is clearly seen floating on top of the $10 \%$ sucrose density step, whereas the $B$. braunii green biomass equilibrated in the vicinity of the $30-50 \%$ sucrose density step, suggesting a cell density of about $1.28 \mathrm{~g} \mathrm{~mL}^{-1}$. Thus, selective removal of the extracellular hydrocarbons from the micro-colonies of the Showa and Kawaguchi-1 strains afforded the cells a much greater density equilibrium property compared to that of the untreated micro-colonies (Fig. 4a and b). The yellow floater band derived from these $B$. braunii B-race strains, i.e., Showa (Fig. 5a) and Kawaguchi-1 (Fig. 5b) consisted of a mixture of botryococcene and carotenoid, having an altogether density lower than that of water $\left(\rho<1 \mathrm{~g} \mathrm{~mL}^{-1}\right)$. The floating botryococcene fraction of Showa appeared to be more yellow compared to the corresponding orange fraction of Kawaguchi-1 (Fig. 5), probably due to the higher carotenoid content in the latter (please see below). The assignments above were further supported by the observation that the amount of the two density equilibrium components (yellow hydrocarbons and green biomass) from these Botryococcus micro-colonies, depended on the amount of sample employed, as well as the duration and power of the mechanical dispersion, suggesting a cause-and-effect relationship between sample size, extent of

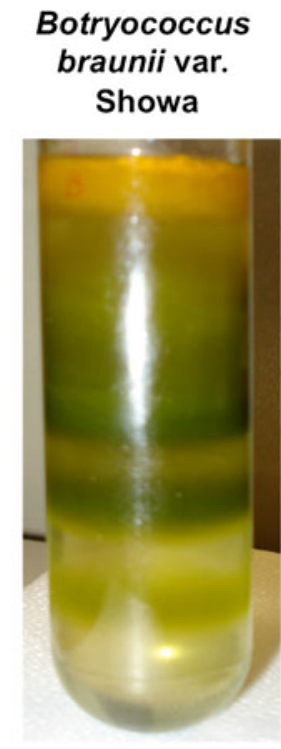

a

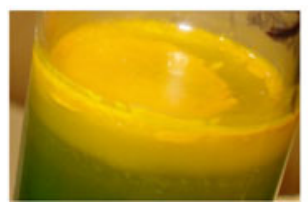

Botryococcus braunii (Kawaguchi-1)

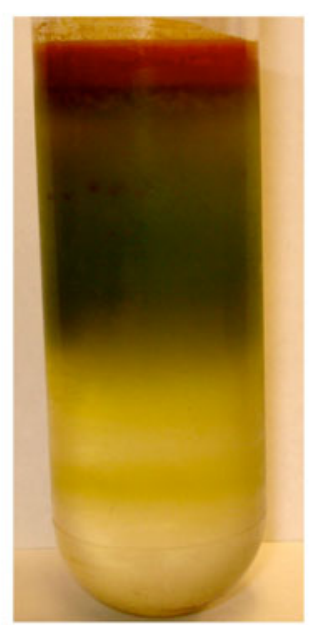

b

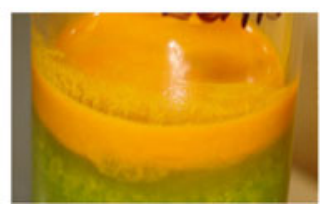

Fig. 5 Aqueous buoyant separation of extracellular hydrocarbons from the Botryococcus biomass following sonication of (a) Botryococcus braunii var. Showa, and (b) Botryococcus braunii Kawaguchi1. A $10-80 \%(\mathrm{w} / \mathrm{v})$ sucrose gradient was employed with a $10 \%$ increment among the gradient steps 
micro-colony dispersion and the amount of yellow and green product. The results affirm that aqueous density equilibrium can be successfully employed to separate extractable hydrocarbons from the Botryococcus micro-colonies.

Table 2 provides estimates of the amount of hydrocarbon accumulation in Showa and Kawaguchi-1, based on the "conservation of mass" principle at constant volume and the application of a system of two equations that relate the density equilibrium values of intact microcolonies, floating hydrocarbons and biomass, devoid of the extractable hydrocarbons. This was achieved upon application of the following system of two equations, which relate buoyant densities and relative amounts of biomass and hydrocarbon content in micro-colony samples (Eroglu and Melis 2009):

$\rho_{S}=\left(x \cdot \rho_{P}\right)+\left(y \cdot \rho_{B}\right)$

$x+y=1$

Eqs. (1) and (2) above require experimental measurement of variables such as:

$\rho_{\mathrm{S}}$ the overall density of the sample, equal to $1.03 \mathrm{~g} \mathrm{~mL}^{-1}$ for Showa and $1.08 \mathrm{~g} \mathrm{~mL}^{-1}$ for Kawaguchi-1 (Table 1).

$\rho_{\mathrm{P}}$ the density of the pure hydrocarbon product, equal to $0.86 \mathrm{~g} \mathrm{~mL}^{-1}$ for both strains (Eroglu and Melis 2009).

$\rho_{\mathrm{B}}$ the density of the respective biomass, devoid of the extractable hydrocarbons, equal to $1.28 \mathrm{~g} \mathrm{~mL}^{-1}$ for both strains (Table 2).

$\mathrm{x}$ is the $\%$ fractional weight of the extractable hydrocarbons in the sample; and

$y \quad$ is the $\%$ fractional weight of the biomass, devoid of extractable hydrocarbons.

Solution of the above system of equations yielded a $30 \%$ and $23 \%(\mathrm{w} / \mathrm{w})$ botryococcene hydrocarbons content in Showa and Kawaguchi-1, respectively (Table 2).

A similar differential extraction of hydrocarbons, upon mechanical dispersion of the micro-colonies, and separation from the respective cellular biomass via sucrose density centrifugation could not be achieved with A-race strains. A variety of glass bead and/or sonication regimens were applied but met with mixed results. In this effort, release of hydrocarbons, presumably $\mathrm{C} 25$ to $\mathrm{C} 31$ odd-numbered n-alkadienes and alkatrienes, occurred in tandem with the release of chlorophyll and other photosynthetic pigments from the cells. A sucrose density centrifugation of such mechanically treated samples resulted in the flotation of hydrocarbons mixed with chlorophyll (not shown). These results suggested that A-race cells, unlike their B-race counterparts, break easily upon mechanical dispersion of the micro-colonies, releasing photosynthetic pigments, which are then mixed with the diene hydrocarbons in the medium.

Spectrophotometric determination of hydrocarbon content in B-race Botryococcus strains

Recent work also employed vortexing wet-cake of Showa micro-colonies with glass beads in the presence of heptane, resulting in the quantitative release of extracellular hydrocarbons from the micro-colonies, and their subsequent solubilization in the heptane phase, without cell disruption and release of green (Chl) pigments (Eroglu and Melis 2010). This heptane-based differential hydrocarbons extraction approach was successfully applied to Showa and Kawaguchi-1 strains in this work.

Absorbance spectra of such heptane extracts, measured in the visible region of the spectrum $(380-520 \mathrm{~nm})$ showed the presence of a carotenoid with fairly similar absorbance characteristics between the two strains (Fig. 6a and b). The heptane extract also showed a distinct absorbance band in the far UV-C $\left(\lambda_{\max }=\sim 190 \mathrm{~nm}\right)$ contributed by the isoprene units in the isolated triterpenoid hydrocarbons. The essence of this work, therefore, is that one can use the distinct spectrophotometric signature of "isoprene units" at $190 \mathrm{~nm}$ (Fig. 6c and d) to quantify triterpenoid botryococcene hydrocarbons, and probably other extractable isoprene oligomeric or polymeric molecules, which may be co-isolated by this method, irrespective of the length of the individual chains (Eroglu and Melis 2010). The absorbance characteristics of the two UV-C spectra were fairly similar between the Showa and Kawaguchi-1 (Fig. 6c and d), suggesting presence of terpenoid hydrocarbons in the two B-race strains.

It was microscopically determined that pyriform-shaped B-race strains of Showa and Kawaguchi-1 remained intact, in spite of the mechanical dispersion of the otherwise tightly formed micro-colony and the selective removal of

Table 2 Spectrophotometric determination of extracellular hydrocarbons from microcolonies of Botryococcus braunii var. Showa and Kawaguchi-1 (B-race).

\begin{tabular}{|c|c|c|c|c|}
\hline \multirow[t]{2}{*}{ Strain } & \multicolumn{2}{|l|}{ Density equilibrium method } & \multicolumn{2}{|c|}{ Spectrophotometric method } \\
\hline & Density of biomass, devoid of Btc, $\rho_{\mathrm{B}},\left(\mathrm{g} \mathrm{mL}^{-1}\right)$ & Btc, $(\%$ of dw $)$ & Btc, $(\%$ of $\mathrm{dw})$ & Carotenoid $(\%$ of $\mathrm{dw})$ \\
\hline B. braunii var. Showa & 1.28 & 30 & 33 & 0.19 \\
\hline B. braunii Kawaguchi-1 & 1.28 & 23 & 21 & 0.49 \\
\hline
\end{tabular}



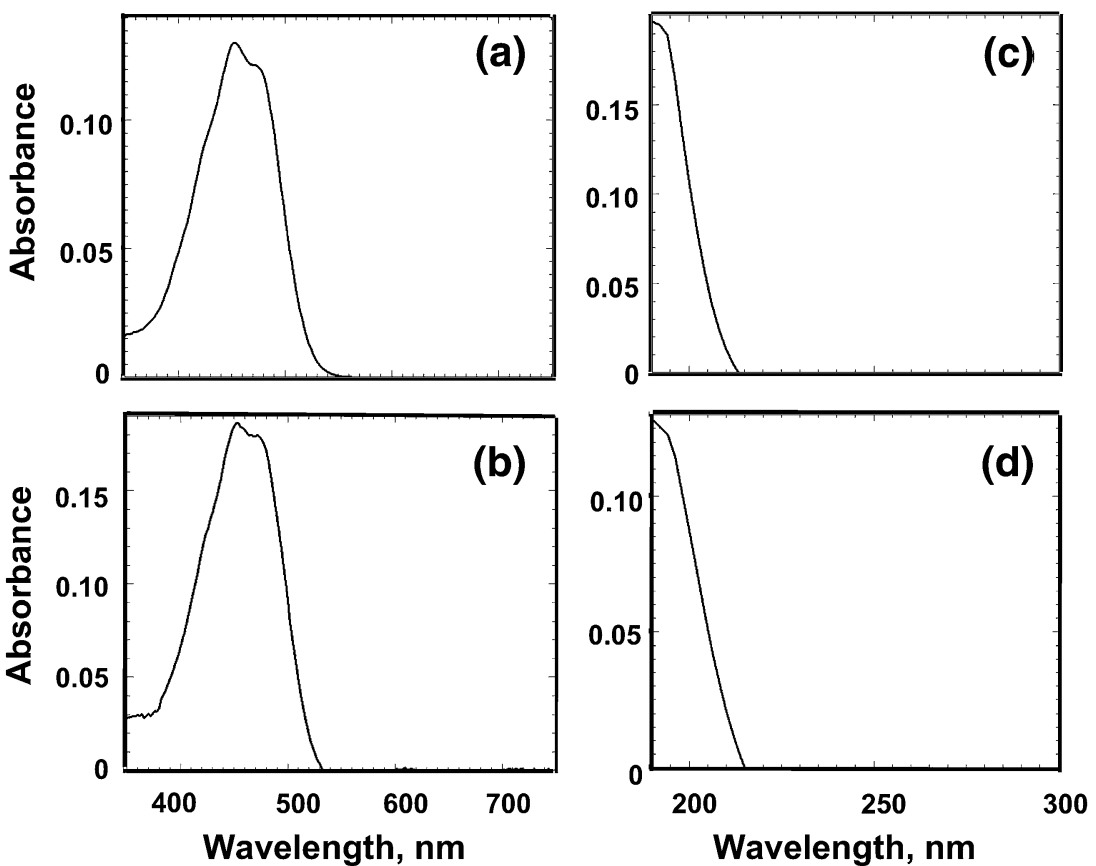

Fig. 6 Absorbance spectra of heptane extracts of Botryococcus braunii var. Showa (a and c), and Botryococcus braunii Kawaguchi1 (b and d) micro-colonies. Absorbance of extracts in the blue (380$520 \mathrm{~nm}$ ) region of the spectrum (a and b) are attributed to extracellular

carotenoids from the two strains. Absorbance of extracts in the far UV $(190-220 \mathrm{~nm})$ region of the spectrum (c and d) are attributed to extracellular botryococcenes from the two strains, respectively

extracellular botryococcene and carotenoids. This specific and quantitative removal and recovery of extracellular hydrocarbons from the B-race strains may serve as a basis for the commercial exploitation of $B$. braunii in the generation and recovery of renewable hydrocarbons.

Only the B-race Showa and Kawaguchi-1 strains were successfully subjected to a selective separation of hydrocarbons from the respective micro-colonies, leaving cells intact in the medium. Attempts at heptane, or other solvent extraction of hydrocarbons from A-race micro-colonies were accompanied by the concomitant release of chlorophyll, shown by the green coloration in the heptane extract. These results are also consistent with the notion that A-race strains, such as those investigated in this work, are more easily subject to cell rupture and pigment release, compared to their B-race counterparts.

Application of suitable molecular extinction coefficients (Eroglu and Melis 2010) permitted quantitative measurement of extracted botryococcenes $[\mathrm{Btc}]$ and carotenoids [Car] from the B-race strains. This was achieved upon application of the following system of equations:

$[B t c]=\left[\left(A_{190} / \varepsilon_{190}\right) x M W_{B t c} x V\right] / m_{d w}$

$[C a r]=\left[\left(A_{450} / \varepsilon_{450}\right) x M W_{C a r} x V\right] / m_{d w}$

where, A: Absorbance, $\varepsilon$ : molar extinction coefficient for botryococcene (at $190 \mathrm{~nm}$ ) and carotenoid (at $450 \mathrm{~nm}$ ) in $\mathrm{mM}^{-1} \mathrm{~cm}^{-1}, \mathrm{MW}_{\mathrm{Btc}}=$ Assumed molecular weight of

botryococcene (410 $\left.\mathrm{g} \mathrm{mol}^{-1}\right)$ and carotenoid $(536 \mathrm{~g} / \mathrm{mol})$, $\mathrm{V}=$ volume of heptane used for extraction $(\mathrm{mL}), \mathrm{m}_{\mathrm{dw}}=$ amount of biomass that was subjected to extraction ( $\mathrm{g}$ dry cell weight). Solution of Eqs. (3) and (4) yields [Btc] and [Car] concentrations in $\mu \mathrm{g} \mathrm{g}^{-1}$ dry cell weight. It should be noted that extractable carotenoids from the Botryococcus strains are probably echinenone, botryoxanthin, braunixanthin, or a mixture thereof (Okada et al. 1997, 1998; Tonegawa et al. 1998). However, molecular extinction coefficients are about the same for most carotenoids and their variants (Eroglu and Melis 2010), justifying the use of a generic extinction coefficient for the Botryococcus carotenoids extracted in the course in this work.

Table 2 (spectrophotometric approach) summarizes the amount of botryococcene that could be extracted from the B-race of Botryococcus species without a concomitant cell lysis. On the basis of these results, it appeared that Showa had a higher content of Btc (33\% Btc per dw), whereas Kawaguchi-1 had 21\% Btc per dw. Conversely, carotenoid content of the Showa extract was $0.19 \%$ of dw, whereas that of Kawaguchi- 1 was $0.49 \%$ of dw. The substantially greater carotenoid content of Kawaguchi-1 relative to Showa caused the more orangey coloration of these microcolonies (Fig. 4b) and of the extractable hydrocarbons fraction (Fig. 5b). Quantitative results from the spectrophotometric measurements (Table 2, right columns) are consistent with those obtained through the densityequilibrium approach (also Table 2, left columns). 
Gravimetric determination of hydrocarbon content in microalgae

Analysis of chlorophyll and carotenoid content on per dw basis for the strains examined is given in Table 3. Chlorophyll content was highest for $C$. reinhardtii $(2.05 \%$ of $\mathrm{dw}$ ) and B. sudeticus (UTEX 2629) (1.6\% of $\mathrm{dw}$ ), whereas it was $0.55 \pm 0.1 \%$ of $\mathrm{dw}$ for the $B$. braunii strains. Thus, B. braunii strains have a lower $\mathrm{Chl} / \mathrm{dw}$ ratio compared to the unicellular microalgae $C$. reinhardtii and B. sudenticus. The lower $\mathrm{Chl} / \mathrm{dw}$ ratio of the former might be a consequence of the unique micro-colonial structure and/or due to the accumulation of hydrocarbons in these microalgae.

Regardless of differences in the $\mathrm{Chl} / \mathrm{dw}$ ratio, all strains examined in this work had similar $\mathrm{Chl} a / \mathrm{Chl} b$ ratios with an average of $2.3 \pm 0.5$ (mol:mol) (Table 3), suggesting similar organization of their photochemical apparatus (Mitra and Melis 2008). Total carotenoid per dw also varied among the strains in a way that was qualitatively similar to that of $\mathrm{Chl}$ (Table 3). However, $\mathrm{Car} / \mathrm{Chl}$ ratios were highest among the hydrocarbon-accumulating $B$. braunii strains and lowest for the non-accumulating strains, including $C$. reinhardtii (Table 3 ). These results are qualitatively consistent with the notion that hydrocarbon accumulation in microalgae is accompanied with a parallel accumulation of carotenoids (Eroglu and Melis 2010).

Total lipophilic extracts in methanol were evaporated to dryness and the dry product was measured gravimetrically (Table 4, column 2). These extracts contained, in addition to any accumulated terpenoid or alkadiene hydrocarbons, membrane lipid diglycerides (DG) and photosynthetic pigments (Chl \& Car). In green microalgae, most of the membrane lipid diglycerides and all pigments (Chl \& Car) originate from the dominant thylakoid membranes, with relatively smaller DG contributions from the plasma membrane, endoplasmic reticulum, Golgi apparatus and mitochondria (Melis et al. 1996). On that basis, and given the similar Chl $a$ / Chl $b$ ratio among the strains examined, it was reasonable to assume a fairly similar total membrane
DG lipid to Chl ratio among all microalgal strains in this study. Thus, the "membrane DG lipid" to Chl ratio parameter was employed as a normalization factor, and served to help us partition the "total lipophilic extract" of the strains into "membrane lipids" and "accumulated terpenoid or alkadiene hydrocarbons", as follows (Table 4).

Chlamydomonas reinhardtii does not accumulate terpenoid or alkadiene hydrocarbon products (Eroglu and Melis 2009) and, consequently, has the lowest "total lipophilic extract" to Chl ratio (10.0:1) among the strains examined (Table 4, column 3). The "total lipophilic extract" in $C$. reinhardtii originates from membrane DG lipids and photosynthetic pigments in the cell. For the analysis below, we assumed that all strains examined have the same membrane DG lipid to Chl ratio $(10.0: 1)$, as in $C$. reinhardtii. This assumption was based on the similar Chl $a / \mathrm{Chl} b$ ratios measured in all strains (Table 3 ), suggesting that all strains have the same organization of thylakoid membranes, hence the same $\mathrm{DG} / \mathrm{Chl}$ ratio. It follows that "total lipophilic extract" to Chl ratios greater than 10:1 would reflect the accumulated terpenoid or alkadiene hydrocarbons (Table 4).

Upon applying the $C$. reinhardtii "total lipophilic extract" to Chl ratio as the "membrane lipid" to Chl ratio in the other microalgae examined, we were able to estimate the membrane lipid content and the extra (accumulated) terpenoid or alkadiene hydrocarbons in the species examined. Results from such partitioning of the "total lipophilic extract" into "membrane lipids" and "accumulated hydrocarbons" are shown in Table 4 (columns 4 and 5). It was determined that Showa and Kawaguchi-1 accumulated about $28.9 \%$ and $19.4 \%$ of their dw, respectively, in the form of extracellular hydrocarbons. The remaining A-race "braunii" strains accumulated $14.1-9.5 \%$ of their dw in the form of such hydrocarbons, whereas B. sudeticus (UTEX 2629) had only baseline levels of extra (accumulated) hydrocarbons.

In greater detail, total lipophilic extract to $\mathrm{Chl}$ ratio for Showa (69.2:1) was much higher than that in $C$. reinhardtii (10.0:1), consistent with the notion of a relatively high

Table 3 Spectrophotometric determination of chlorophyll and total carotenoid content in various Botryococcus species and Chlamydomonas reinhardtii (CC503).

\begin{tabular}{|c|c|c|c|c|}
\hline Strain & Total Chl, $(\%$ of dw $)$ & Chl $a$ / Chl $b$ (mol:mol) & Total Car, $(\%$ of dw) & Car / Chl (w:w) \\
\hline B. braunii var. Showa & 0.49 & 2.2 & 0.21 & 0.43 \\
\hline B. braunii Kawaguchi-1 & 0.86 & 2.3 & 0.54 & 0.63 \\
\hline B. braunii Yamanaka & 0.39 & 2.0 & 0.10 & 0.26 \\
\hline B. braunii UTEX 2441 & 0.38 & 2.5 & 0.19 & 0.50 \\
\hline B. braunii UTEX LB572 & 0.64 & 2.1 & 0.13 & 0.20 \\
\hline B. sudeticus (UTEX 2629) & 1.60 & 2.9 & 0.42 & 0.26 \\
\hline C. reinhardtii (CC503) & 2.05 & 2.2 & 0.37 & 0.18 \\
\hline
\end{tabular}


Table 4 Total amount of lipophilic extract, lipophilic extract to chlorophyll ratios, and estimates of intracellular lipids and accumulated hydrocarbons in various Botryococcus strains and Chlamydomonas reinhardtii

\begin{tabular}{|c|c|c|c|c|}
\hline Strain & $\begin{array}{l}\text { Total lipophilic extract } \\
\text { (\% of dw) }\end{array}$ & $\begin{array}{l}\text { Total lipophilic extract } \\
\text { to Chl ratio, w/w }\end{array}$ & $\begin{array}{l}\text { Membrane lipids } \\
\text { ( } \% \text { of } d w)\end{array}$ & Accumulated hydrocarbons ( $\%$ of $d w)$ \\
\hline B. braunii var. Showa & 33.9 & 69.2 & 5.0 & 28.9 \\
\hline B. braunii Kawaguchi-1 & 28.4 & 33.0 & 9.0 & 19.4 \\
\hline B. braunii Yamanaka & 18.0 & 46.2 & 3.9 & 14.1 \\
\hline B. braunii UTEX 2441 & 16.7 & 44.0 & 3.9 & 12.8 \\
\hline B. braunii UTEX LB572 & 15.9 & 24.8 & 6.4 & 9.5 \\
\hline B. sudeticus (UTEX 2629) & 19.3 & 12.0 & 16.1 & 3.2 \\
\hline C. reinhardtii (CC503) & 20.5 & 10.0 & 20.5 & - \\
\hline
\end{tabular}

extracellular botryococcene present in the former (Eroglu and Melis 2010). Total lipophilic extract in Showa partitioned into $5.01 \%$ membrane lipids and $28.9 \%$ accumulated hydrocarbons. The total lipophilic extract to Chl ratio was intermediate for Kawaguchi-1 (33.0:1), partitioning in $8.97 \%$ membrane lipids and $19.4 \%$ accumulated hydrocarbons. A-race strains Yamanaka, UTEX 2441, and UTEX LB572 had total lipophilic extract to $\mathrm{Chl}$ ratio in the 24.8-46.2:1 range, resulting in estimates of accumulated hydrocarbons in the 1319\% range (Table 4). Botryococcus sudeticus (UTEX 2629) had a rather low total lipophilic extract to Chl ration (12.0:1) suggesting that this strain was poor in accumulated hydrocarbons. In summary, the higher "total lipophilic extract" / Chl ratio in the $B$. braunii strains reflects the accumulation of terpenoid or alkadiene hydrocarbon products. It may thus be concluded that all "braunii" strains synthesize and accumulate hydrocarbons above and beyond those that are encountered as membrane lipids, so as to attain "total lipophilic extract" to Chl ratio $>10.0: 1$.

\section{Discussion}

Green microalgae of the genus Botryococcus are unique among photosynthetic microorganisms as they constitutively synthesize, accumulate, and secrete substantial amounts of their photosynthate as alkadiene (A-race microalgae) or tri-terpenoid (B-race microalgae) hydrocarbons. However, a direct quantitative analysis of the productivities by various Botryococcus strains is missing from the literature. For example, Sawayama et al. (1994) reported a biomass accumulation rate of only about $28 \mathrm{mg} \mathrm{dw} \mathrm{L} \mathrm{L}^{-1} \mathrm{~d}^{-1}$ from the culture of $B$. braunii UTEX LB572, grown in secondarily treated sewage in a continuous bioreactor system. Also working with the UTEX LB572 strain, grown in secondarily treated piggery wastewater in a batch reactor, An et al. (2003) reported biomass yield of $\sim 8.5 \mathrm{~g} \mathrm{dw} \mathrm{L}^{-1}$ and about $0.95 \mathrm{~g}$ hydrocarbon $\mathrm{L}^{-1}$ after 12-day batch cultivation. On the other hand, upon growth in flasks under orbital shaking, Vazquez-Duhalt and Arredondo-Vega (1991) reported biomass yield of about $300 \mathrm{mg} \mathrm{dw} \mathrm{L} \mathrm{L}^{-1}$ for both the B. braunii Austin and Göttingen strains (ARace) following 28-day batch cultivation. Dayananda et al. (2005) cultivated B. braunii var. SAG 30.81 under diurnal (16 h light: $8 \mathrm{~h}$ dark) cycles in orbitally shaken conical flasks and reported a yield of $650 \mathrm{mg} \mathrm{dw} \mathrm{L}{ }^{-1}$ after 30-day batch cultivation. It is evident from these results that $B$. braunii growth conditions, including bioreactor design and growth media composition, substantially affect the productivity of the cultures. Work in this manuscript presented, for the first time, comparative hydrocarbon productivities in cultures of six different Botryococcus strains, grown under identical experimental conditions.

Density equilibrium analysis (Table 1 ; Fig. 4) showed that $B$. braunii var. Showa microcolonies have the lowest density equilibrium of all the strains examined in this study. This is consistent with findings by Nonomura (1988) who provided evidence that Showa differs from other members of the Chlorococcales in terms of the production of high concentrations of liquid hydrocarbons, i.e., C30-C34 botryococcenes (Sato et al. 2003; Okada et al. 2004; Metzger and Largeau 2005). This property apparently confers to Showa the relatively low-density equilibrium and high buoyancy observed.

Gravimetric results given in Table 4 are consistent with the density equilibrium (Table 2, 3rd column) and spectrophotometric (Table 2, 4th column) quantitation of hydrocarbons in the samples examined. These results are also consistent with measurements in the literature. For example, Wolf et al. (1985) reported that B. braunii var. Showa accumulates $24-29 \%$ of its dry biomass in the form botryococcene hydrocarbons. Yamaguchi et al. (1987) measured $34 \mathrm{~g}$ hydrocarbons per $100 \mathrm{~g} \mathrm{dw}$ from the $B$. braunii Berkeley (Showa) strain. Nonomura (1988) reported greater botryococcene hydrocarbon content in Showa $(30 \%$, or more, per dry cell weight) than that in other strains of B. braunii (1.5 to $20 \%$ ). Okada et al. (1995) also showed that B. braunii Kawaguchi-1 and 
Yamanaka micro-colonies accumulate hydrocarbons in the range of $18.8 \pm 0.8$ and $16.1 \pm 0.3 \%$ of dry cell weight, respectively.

Multiple independent hydrocarbon quantitation methods on a variety of Botryococcus strains have not been applied before. Accordingly, Botryococcus productivity comparisons in the literature are based on sometimes substantially different quantitation methods. Work in this manuscript tested and validated the applicability of three different and independent approaches and measurements for the quantitative measurement of hydrocarbons in various strains of the green microalgae Botryococcus. These methods were applied to six different strains of Botryococcus, belonging either to the Arace or B-race. Included were (i) density equilibrium of intact micro-colony measurements, (ii) spectrophotometric quantitation of extracellular hydrocarbons, and (iii) gravimetric measurements of the extracts. All three analytical methods yielded comparable quantitative results. Evidence revealed that the B-race microalgae B. braunii var. Showa and Kawaguchi-1 accumulated the highest amount of hydrocarbons per dry weight biomass, equivalent to about $30 \%$ (w:w) and 20\% (w:w), respectively. Methods in this work will find important application in high throughput screening and selection of microalgae with substantial hydrocarbon productivity for commercial exploitation.

Open Access This article is distributed under the terms of the Creative Commons Attribution Noncommercial License which permits any noncommercial use, distribution, and reproduction in any medium, provided the original author(s) and source are credited.

\section{References}

An JY, Sim SJ, Lee JS, Kim BW (2003) Hydrocarbon production from secondarily treated piggery wastewater by the green alga Botryococcus braunii. J Appl Phycol 15(2/3):185-191

Bachofen R (1982) The production of hydrocarbons by Botryococcus braunii. Experientia 38:47-49

Bailliez C, Largeau C, Casadevall E, Yang LW, Berkaloff C (1988) Photosynthesis, growth and hydrocarbon production of Botryococcus braunii immobilized by entrapment and adsorption in polyurethane foams. Appl Microbiol Biot 29:141-147

Banerjee A, Sharma R, Chisti Y, Banerjee UC (2002) Botryococcus braunii: a renewable source of hydrocarbons and other chemicals. Crit Rev Biotechnol 22(3):245-279

Beakes GW, Cleary AL (1999) Visualization of plastids and lipophilic components in living colonies of a wild strain of the hydrocarbon-forming, green alga Botryococcus by laser scanning confocal microscopy. J Appl Phycol 10:435-446

Brown AC, Knights BA, Conway E (1969) Hydrocarbon content and relationship to physiological state in the green alga Botryococcus braunii. Phytochemistry 8:543-547

Dayananda C, Sarada R, Bhattacharya S, Ravishankar GA (2005) Effect of media and culture conditions on growth and hydrocarbon production by Botryococcus braunii. Process Biochem 40 (9):3125-3131
de-Bashan LE, Bashan Y (2010) Immobilized microalgae for removing pollutants: review of practical aspects. Bioresour Technol 101(6):1611-1627

Eroglu E, Melis A (2009) "Density equilibrium" method for the quantitative and rapid in situ determination of lipid, hydrocarbon, or biopolymer content in microorganisms. Biotechnol Bioeng 102(5):1406-1415

Eroglu E, Melis A (2010) Extracellular terpenoid hydrocarbon extraction and quantitation from the green microalgae Botryococcus braunii var. Showa. Bioresour Technol 101(7):2359-2366

Grice K, Schouten S, Nissenbaum A, Charrach J, Sinningh Damsté JS (1998) A remarkable paradox: sulfurised freshwater algal (Botryococcus braunii) lipids in an ancient hypersaline euxinic ecosystem. Org Geochem 28(3-4):195-216

Kita K, Okada S, Sekino H, Imou K, Yokoyama S, Amano T (2010) Thermal pre-treatment of wet microalgae harvest for efficient hydrocarbon recovery. Appl Energ 87(7):2420-2423

Komárek J, Marvan P (1992) Morphological differences in natural populations of the genus Botryococcus (Chlorophyceae). Arch Protistenkd 141:65-100

Largeau C, Casadevall E, Berkaloff C, Dhamelincourt P (1980) Sites of accumulation and composition of hydrocarbons in Botryococcus braunii. Phytochemistry 19(6):1043-1051

Lee J-Y, Yoo C, Jun S-Y, Ahn C-Y, Oh H-M (2010) Comparison of several methods for effective lipid extraction from microalgae. Bioresour Technol 101:S75-S77

Lichtenthaler HK, Buschmann C (2001) Chlorophylls and carotenoids: measurement and characterization by UV-VIS spectroscopy. In: Wrolstad RE (ed) Current protocols in food analytical chemistry. John Wiley \& Sons Inc, New York, pp F4.3.1-F4.3.8

Lupi FM, Fernandes HML, Tomé MM, Sá-Correia I, Novais JM (1994) Influence of nitrogen source and photoperiod on exopolysaccharide synthesis by the microalga Botryococcus braunii UC 58. Enzyme Microb Tech 16:546-550

Melis A, Murakami A, Nemson JA, Aizawa K, Ohki K, Fujita Y (1996) Chromatic regulation in Chlamydomonas reinhardtii alters photosystem stoichiometry and improves the quantum efficiency of photosynthesis. Photosynth Res 47:253-265

Metzger P, Casadevall E (1987) Lycopadiene, a tetraterpenoid hydrocarbon from new strains of the green alga Botryococcus braunii. Tet Lett 28:3931-3934

Metzger P, Largeau C (2005) Botryococcus braunii: a rich source for hydrocarbons and related ether lipids. Appl Microbiol Biot 66 (5):486-496

Metzger P, Casadevall E, Coute A (1988) Botryococcene distribution in strains of green alga Botryococcus braunii. Phytochemistry 27:1383-1388

Mitra M, Melis A (2008) Optical properties of microalgae for enhanced biofuels production. Opt Express 16(26):21807-21820

Nonomura AM (1988) Botryococcus braunii var. Showa (Chlorophyceae) from Berkeley, California, United States of America. Jpn J Phycol 36:285-291

Okada S, Murakami M, Yamaguchi K (1995) Hydrocarbon composition of newly isolated strains of green microalga Botryococcus braunii. J Appl Phycol 7(6):555-559

Okada S, Tonegawa I, Matsuda H, Murakami M, Yamaguchi K (1997) Braunixanthins 1 and 2, new carotenoids from the green microalga Botryococcus braunii. Tetrahedron 53(33):11307-11316

Okada S, Tonegawa I, Matsuda H, Murakami M, Yamaguchi K (1998) Botryoxanthin B and alpha-botryoxanthin A from the green microalga Botryococcus braunii Kawaguchi-1. Phytochemistry 47(6):1111-1115

Okada S, Devarenne TP, Murakami M, Abe H, Chappell J (2004) Characterization of botryococcene synthase enzyme activity, a squalene synthase-like activity from the green microalga Botryococcus braunii, race B. Arch Biochem Biophys 422:110-118 
Park I-S, Kim D-I (1993) Significance of fresh weight to dry cell weight ratio in plant cell suspension cultures. Biotechnol Tech $7: 627-630$

Raja R, Hemaiswarya S, Kumar NA, Sridhar S, Rengasamy R (2008) A perspective on the biotechnological potential of microalgae. Crit Rev Microbiol 34(2):77-88

Rao AR, Dayananda C, Sarada R, Shamala TR, Ravishankar GA (2007) Effect of salinity on growth of green alga Botryococcus braunii and its constituents. Bioresour Technol 98(3):560-564

Samori C, Torri C, Samorì G, Fabbri D, Galletti P, Guerrini F, Pistocchi R, Tagliavini E (2010) Extraction of hydrocarbons from microalga Botryococcus braunii with switchable solvents. Bioresour Technol 101(9):3274-3279

Sato Y, Ito Y, Okada S, Murakami M, Abe H (2003) Biosynthesis of the triterpenoids, botryococcenes and tetramethylsqualene in the B race of Botryococcus braunii via the non-mevalonate pathway. Tet Lett 44:7035-7037

Sawayama S, Inoue S, Yokoyama S (1994) Continuous culture of hydrocarbon-rich microalga Botryococcus braunii in secondarily treated sewage. Appl Microbiol Biot 41(6):729-731

Sawayama S, Inoue S, Dote Y, Yokoyama SY (1995) $\mathrm{CO}_{2}$ fixation and oil production through microalga. Energ Convers Manage $36: 729-731$
Senousy HH, Beakes GW, Hack E (2004) Phylogenetic placement of Botryococcus braunii (Trebouxiophyceae) and Botryococcus sudeticus isolate UTEX 2629 (Chlorophyceae). J Phycol 40:412-423

Tonegawa I, Okada S, Murakami M, Yamaguchi K (1998) Pigment composition of the green microalga Botryococcus braunii Kawaguchi-1. Fish Sci 64(2):305-308

Vazquez-Duhalt R, Arredondo-Vega BO (1991) Haloadaptation of the green alga Botryococcus braunii (race A). Phytochemistry 30:2919-2925

Wake LV, Hillen LW (1980) Study of a "bloom" of the oil-rich alga Botryococcus braunii in the Darwin River Reservoir. Biotechnol Bioeng 22:1637-1656

Ward MA (1970) Whole cell and cell-free hydrogenases of algae. Phytochemistry 9:259-266

Wolf FR, Cox ER (1981) Ultrastructure of active and resting colonies of Botryococcus braunii (Chlorophyceae). J Phycol 17:395-405

Wolf FR, Nonomura AM, Bassham JA (1985) Growth and branched hydrocarbon production in a strain of Botryococcus braunii (Chlorophyta). J Phycol 21:388-396

Yamaguchi K, Nakano H, Murakami M, Konosu S, Nakayama O, Kanda M, Nakamura A, Iwamoto H (1987) Lipid composition of a green alga, Botryococcus braunii. Agr Biol Chem Tokyo 51(2):493-498 